\title{
Current practices and attitudes of family physicians toward substance use disorders in the Emirate of Abu Dhabi: a cross-sectional survey in primary care
}

Amna Al Marzouqi ${ }^{1}$, Catriona Matheson'2, Hanan Al Hashmi1, Rekha Ann Thomas $^{3}$, Amanda J Lee ${ }^{2}$, Christine Bond ${ }^{2}$, Hamad Al Ghafri ${ }^{1}$, Ahmed ElKashef ${ }^{1}$.

${ }^{1}$ Department of Research and Studies, National Rehabilitation Center, Abu Dhabi, the United Arab Emirates; ${ }^{2}$ Division of Applied Health Sciences, University of Aberdeen, Aberdeen AB252ZD, Scotland, UK; ${ }^{3}$ Institute of Public Health, College of Medicine \& Health Sciences, UAE University, Al Ain, The United Arab Emirates.

Correspondence: email: Amna.almarzouqi@nrc.ae

\section{Abstract}

\section{Background}

Primary care clinics are the ideal setting to treat individuals with Substance Use Disorders (SUD). However, in most societies including the United Arab Emirates (UAE), the level and type of treatment provided by physicians in primary care is unknown. This study aims to assess the attitudes and beliefs of primary care physicians towards the treatment of patients with SUD.

\section{Methods}

A cross-sectional electronic survey was distributed to 231 physicians across 35 primary healthcare clinics in the Emirate of Abu Dhabi. The survey questionnaire captured data on four main areas including demographic and practice characteristics of the physicians, practice patterns of the physicians, training, and attitudes towards drug dependency treatment.

\section{Results}

The response rate was $46 \%$. There were more females (59\%) and the mean (standard deviation) age of participants was 46.4 (9.5) years. Only $8.7 \%$ of physicians treated people with SUDs. Most of the physicians (93.2\%) did not have specialised training in treating SUDs. A total $66 \%$ of physicians were interested in obtaining further training in screening and management of SUDs.

\section{Conclusion}

This study identifies the need to implement training for physicians in diagnosing and further managing patients with addiction.

Keywords: Substance Use Disorders, primary care, screening, counselling, continuing medical education 


\section{Introduction}

Alcohol and other substances liable to be misused, such as cocaine, opioid, and cannabis are a global public health problem associated with various adverse societal, personal, economic and health consequences, including significant rates of morbidity and mortality.

According to estimates of the United Nations Office on Drugs and Crime (UNODC), in 2010 the number of 'problem drug users' (those using illicit substances) was between 15.5 and 38.6 million.1 Globally, alcohol use is the third leading risk factor leading to disease and the eighth leading cause of death. Deaths related to substance misuse were 7.6 million in 2009 (illicit drugs 0.245 million, alcohol 2.3 million, tobacco 5.1 million). ${ }^{2}$

This paper is focused on SUDs concerning drugs and alcohol and excludes the misuse of tobacco.

An increasing body of evidence now supports the effectiveness of delivering brief interventions in primary care to reduce the use of alcohol3-5 and other drugs., ${ }^{3,4}$ Nevertheless, many studies have revealed that Family Physicians (FP) lack awareness and knowledge about alcohol and substance use in the primary care setting. ${ }^{6}$

Studies in the UK and the USA demonstrate that the attitude of the wider population of general practitioners to treating drug users is primarily negative..$^{7-10}$

In the Emirate of Abu Dhabi (EAD), Primary Healthcare Services (PHC) are delivered in an outpatient care setting. They are regulated by the Ambulatory Health Services which comes under an Abu Dhabi Health Services Company called SEHA, established to manage public hospitals and clinics in the Emirate of Abu Dhabi. There is a total of 40 PHCs distributed in different regions of Abu Dhabi. ${ }^{11}$

Despite the increase in drug and alcohol abuse in the $\mathrm{UAE}^{12}$, the extent and nature of the FPs involvement in the treatment of substance mis-users and their attitudes and beliefs are unknown. There is a need to identify trends in the primary care management of patients facing drug and/or alcohol problems in the UAE, in order to get the educational needs they may require to further develop community services for drug and alcohol users.

The aim of the study was is to assess the attitudes, current levels of involvement of FPs regarding treatment of patients with SUDs and identifying their associated training needs. The results of the study are expected to provide baseline data prior to implementation of a formal screening and treatment programme in the UAE. 


\section{Methods}

This was a cross-sectional self-completed electronic survey. The setting was governmental primary healthcare facilities in the Emirate of Abu Dhabi excluding dental healthcare services, maternal and child healthcare services, urgent care, occupational health and screening services, home healthcare and private sector clinics ( $\mathrm{n}=35)$. The participants were the FPs based in these settings $(\mathrm{n}=231)$.

The sample frame was all eligible PHC facilities in the EAD. The questionnaire was sent to the lead physicians who then distributed it to all the FPs in each centre.

The questionnaire was based on a validated instrument developed and used by some of the authors to assess the attitudes of Scottish general practitioners in 2000 and 2008. ${ }^{9,13}$ The local research team adapted the tool to suit the UAE culture. The final questionnaire captured data on four main areas: demographics and practice characteristics of the FPs, practice patterns of the FPs, training and attitudes towards drug dependency treatment within the general practice. The survey was formatted with fixed choice options with an 'other' option and Likert scales.

The survey was piloted in seven PHC clinics where the IRB approval was first obtained across the Abu Dhabi region. The total number of FPs was 70, and 38 responded. After minor changes the final version of the questionnaire was distributed to the remaining 28 PHCs in the EAD.

The survey was sent via email to the lead physician in each clinic, who in turn forwarded it to all FPs within their clinic. Three electronic reminders were sent at four weekly intervals by the team to the lead physician. Response was either by return of the completed electronic questionnaire or hard copy to the lead physician, who collated and returned them to the National Rehabilitation Centre.

All data was entered into an access database then exported to SPSS for storing, data cleaning and statistical analysis. Descriptive statistics [frequencies, mean (standard deviation, SD), median (interquartile range, IQR) or \% (n)] of data are presented. All data entry corrections, including missing values, incorrect or out of range (outliers) values or responses that were inconsistent with other responses in the database were reviewed by a statistician. Percentages relate to the total number who answered the questions, and not the total sample.

The study protocol was approved by four Institutional Review Boards/ Human Research Ethics Committees: SKMC (reference number REC-19.01.2012 [RS195] On 19 January 2012), United Arab Emirates University- Faculty of Medicine and Health Sciences (12/13CRD164 on 3 May 2012), AHS (same as United Arab Emirates University on 17 May, 2012), and Al Gharbia Hospitals (by reference number AGH-IREC-012-02 on 15 October, 2012). 


\section{Results}

\section{Response rate and demography}

The questionnaire was completed by 106 FPs. The overall response was $46 \%$ (106/231); 18 of 28 sites (64\%) did not return any questionnaires. The mean age of responders was 46.4 years (standard deviation (SD) 9.5), 90\% (60/67) had been born outside the UAE, and 54\% (57/106) were working in Abu Dhabi. The majority of respondents were female (59\%; 62/105)). On average, respondents had 19.2 years (SD 9.4) of experience each (> 20 years' experience: 40\%; 20-30 years: 33\%; and $>30$ years: 19\%). The median (IQR) number of patients seen per week by the PHC was 140 (100-176) (Table 1).

\section{Table 1. Demography of Respondents}

\begin{tabular}{|c|c|c|c|}
\hline Feature & Group & $\%$ & $\mathrm{n}$ \\
\hline \multirow[t]{2}{*}{ Gender } & Male & 41 & 43 \\
\hline & Female & 59 & 62 \\
\hline \multirow{5}{*}{ Age (yrs) } & $<30$ & 1 & 1 \\
\hline & $30-39$ & 25 & 16 \\
\hline & $40-49$ & 30 & 19 \\
\hline & $50-59$ & 38 & 24 \\
\hline & $\geq 60$ & 6 & 4 \\
\hline \multirow{3}{*}{ Years of experience } & $<20$ & 48 & 49 \\
\hline & $20-30$ & 33 & 34 \\
\hline & $>30$ & 19 & 19 \\
\hline \multirow{2}{*}{ Place of birth } & UAE & 10 & 7 \\
\hline & Outside UAE & 90 & 60 \\
\hline \multirow{2}{*}{ Location } & Abu Dhabi & 54 & 57 \\
\hline & Al Ain & 46 & 49 \\
\hline
\end{tabular}




\section{Practice patterns of the family physicians}

Only 8.7\% (9/104) of responders were currently treated people with SUD. There were only 55 responses to the question about perceived comfort level in treating SUDs. Around 58\% (32/55) of these reported a neutral comfort level, 25.5\% $(14 / 55)$ felt very or somewhat uncomfortable and $16.4 \%(9 / 55)$ felt very or somewhat comfortable. Of the 34 responses to the question on the most commonly seen SUD, drug and alcohol use was reported by $47 \%(16 / 34)$, tramadol 15\% (5/34), benzodiazepine 12\% (4/34), others included antihistamines, gabapentin, opiates, and artane 26\% (9/34).

With regard to use of guidelines in treating SUD patients, 60\% (58/96) did not refer to any clinical guidelines. Of those using guidelines (38/96), nine indicated brief interventions, eight indicated the use of psychotherapy, five indicated using medication management and 32 referred patients to specialist treatment. More than half of those who responded (52\%, or 55/106), did not provide any kind of treatment options. Out of the 82 family physicians who responded to a question on urine testing, $64.6 \%$ (53/82) never carried out urine testing and only a small proportion (18.3\% or 15/82)) carried out urine tests upon request for the purpose of pre-employment, pre-university enrolment, etc. A total 75\% (64/106) of responders carried out HIV screening, 65.6\% (42/64) carried out hepatitis B screening and $60.9 \%$ (39/64) carried out hepatitis C screening. The majority of family physicians offered hepatitis B vaccination for their patients $(82.5 \%$ or 47/57) and only 14.5\% (8/55) offered hepatitis A vaccination (Table 2).

Table 2. Practice patterns of family physicians

\begin{tabular}{|l|l|}
\hline Practice patteru & $0^{0}$ (n) \\
\hline Treatment options offered to dung abusers in general practice* & \\
\hline Psycho-stimulant drugs & $0.9(1)$ \\
\hline Benzodiazepine & $1.9(2)$ \\
\hline Referral to residential detox program & $23.4(25)$ \\
\hline Counselling services & $37.7(40)$ \\
\hline None of the above & $51.9(55)$ \\
\hline Frequency of caurying umine testing in primary care (N=82) & \\
\hline Regularly & $2.4(2)$ \\
\hline Hardly ever & $15.9(13)$ \\
\hline Never & $63.4(52)$ \\
\hline Upon request (pre-employment, pre-university, etc ) & $18.3(15)$ \\
\hline
\end{tabular}

Responders could select more than one option. 


\section{Training}

The majority of the FPs (93.2\% or 96/103) did not have any specialised training in treating drug and alcohol abusers (Table 3). A total 66\% (50/76) would have liked to have had further training in screening and the management of substance abuse. The most popular and common training topics among FPs were drug dependency screening, treatment, and management in primary care, which was 54.5\% (24/44).

Table 3. Family physicians' specialised training/ expertise in addiction

\section{management}

\begin{tabular}{|c|c|c|}
\hline $\begin{array}{l}\text { Training in addiction } \\
\text { management }\end{array}$ & $\%$ (n) & Valid $\mathbf{n}$ \\
\hline $\begin{array}{l}\text { Staff in practice have } \\
\text { specialised training/ expertise } \\
\text { in addiction management }\end{array}$ & $4.5(4)$ & 89 \\
\hline $\begin{array}{l}\text { Physicians have ever received } \\
\text { specific training }\end{array}$ & $6.8(7)$ & 103 \\
\hline - Drug training course & 0 & 106 \\
\hline - Postgraduate course & 0 & 106 \\
\hline - Specialist training & 0 & 106 \\
\hline - Joumal articles & $3.7(4)$ & 106 \\
\hline - Distance learning & $1.8(2)$ & 106 \\
\hline - Others & $\begin{array}{l}2.8 \text { (3) Family residence training } \\
\text { programme (1), undergraduate family } \\
\text { programme (1), work in inpatient (1) }\end{array}$ & 106 \\
\hline $\begin{array}{l}\text { Training content I would like to } \\
\text { cover: }\end{array}$ & $\begin{array}{l}\text { Drug dependency screening, treatment, } \\
\text { and management in primary care. } 54.5 \\
\text { (24) } \\
\text { Counselling and psychological } \\
\text { management for drug addiction. } 31.8 \text { (14) } \\
\text { Workshops and conferences for enhancing } \\
\text { knowledge about common disorders of } \\
\text { substance abuse. } 13.6 \text { (6) }\end{array}$ & 44 \\
\hline
\end{tabular}




\section{FPs' attitudes toward drug dependency}

Around 50\% (47/98) of those who responded believed that prescribing controlled drugs was part of a family physician's job and more than $50 \%$ (53/103) believed that drug users who visited the clinic would not discourage other patients.

A total $70 \%$ (73/104) thought that drug users should be seen centrally by specialist services and around 50\% (49/101) reported that they were less confident in the success of treating poly-drug users.

With regard to access to healthcare services by drug user patients, $74.5 \%$ (67/102) believed that 'treating drug abusers in primary care' should not affect a patient's access to healthcare services'. Also, 86.3\% (88/103) agreed that 'a holistic approach is essential to ensure success of a care plan' (Table 4).

\section{Table 4. Attitude of FPs towards drug dependency treatment in general practice}

\begin{tabular}{|c|c|c|c|c|}
\hline Attitude & Valid n & $\begin{array}{l}\text { Strongly } \\
\text { agree or } \\
\text { agee }\end{array}$ & Uncertain & $\begin{array}{l}\text { Strongly } \\
\text { disagee or } \\
\text { disagee }\end{array}$ \\
\hline $\begin{array}{l}\text { Prescribing controlled drugs is } \\
\text { part of an FP's professional remit }\end{array}$ & 98 & $48(47)$ & $22.4(22)$ & $29.6(29)$ \\
\hline $\begin{array}{l}\text { Drug abusers visiting the clinic } \\
\text { will discourage other patients }\end{array}$ & 103 & $19.4(20)$ & $29.1(30)$ & $51.5(53)$ \\
\hline $\begin{array}{l}\text { Drug abusers should be seen } \\
\text { centrally by specialist services, } \\
\text { rather than in general practice }\end{array}$ & 104 & $70.2(73)$ & $11.5(12)$ & $18.3(19)$ \\
\hline $\begin{array}{l}\text { Less confident in the success of } \\
\text { any treatment if the patient is a } \\
\text { poly-drug user }\end{array}$ & 101 & $48.5(49)$ & $34.7(35)$ & $16.8(17)$ \\
\hline $\begin{array}{l}\text { Treating drug dependency } \\
\text { should not affect patient's access } \\
\text { to healthcare services }\end{array}$ & 102 & $74.5(76)$ & $10.8(11)$ & 14.7 (15) \\
\hline $\begin{array}{l}\text { A holistic approach is necessary } \\
\text { for any care plan to be successful }\end{array}$ & 103 & $86.3(88)$ & $8.8(9)$ & $4.9(5)$ \\
\hline
\end{tabular}




\section{Discussion}

Results exhibit the low level (less than 10\%) of current involvement by family physicians in the management of SUDs. Most of those who responded felt neutral in their 'comfort level' about managing this group, 1/4th reported feeling uncomfortable, but around 1/8th felt comfortable in dealing with SUDs. This could be due to lack of knowledge or training in this field or lack of experience.

More than $90 \%$ of family physicians had no specialised training in SUDs and a large number required further training.

There was evidence of gaps between attitude and practice. Although the majority of those who responded believed that prescribing controlled drugs was part of general medical practice and drug users visiting the clinic would not affect other patients' access, $70 \%$ believed treatment should be provided centrally by specialists. This is similar to findings in other parts of the world ${ }^{14,15}$ and could be attributed partially to a lack of confidence in the success of treating poly-drug users, a lack of guidelines or potential stigmatisation of this patient group.

Use of clinical guidelines in clinical practice of primary care is minimal. One important reason for this is that mental health problems including substance use ranks low in the priority list of general practice. The top priorities are for other medical illnesses like diabetes, hypertension, etc. Furthermore, guidelines alone will not influence the pattern of clinical practice; it has to be accompanied with training in order to be publicised. ${ }^{16}$ Stigma and cultural factors could also contribute to not addressing these issues in general practice. This has been shown to exist in primary care in other countries ${ }^{17}$ and requires further probing in the Arab and UAE contexts.

Involvement of FPs in treating drug and alcohol users in PHC in EAD is low (8.7\%) compared to the Scottish study (43.7\%). ${ }^{13}$ In another study conducted in Sri Lanka, the majority of GPs did not feel confident of their ability to detect $(60 \%)$ or manage (55.2\%) alcohol misuse. ${ }^{18}$ In the PHC, the screening rate for HIV $(75 \%, n=64)$, hepatitis B $(65 \%, n=64)$ and hepatitis C $(60.9 \%, n=64)$ was relatively similar to the Scottish study which indicated that GPs routinely provided screening for HIV (70.1\%), hepatitis B (76.4\%), and hepatitis C (70.1\%). Regarding vaccination, Abu Dhabi FPs offered hepatitis B vaccination for $82.5 \%(n=57)$, a figure that was higher than for Scottish GPs $(60.6 \%)$. The case was opposite for hepatitis C, where only $14.5 \%$ of the 55 responding Abu Dhabi FPs offered vaccination, while $48.5 \%$ of Scottish GPs offered vaccination. ${ }^{13}$ Around 33\% (32/96) of FPs in Abu Dhabi referred patients to specialists. In contrast, $16.3 \%$ of GPs in Scotland said patients were seen by specialist service nurses in practice. ${ }^{13}$ In another study, $19.1 \%$ always referred the patient to a 
physician, $17 \%$ to a psychiatrist, and $13.3 \%$ to a centre dealing with alcohol related problems ${ }^{18}$ The most commonly seen substance misuse in Abu Dhabi was alcohol, followed by tramadol and benzodiazepine. Others included antihistamines, gabapentin, opiates, and artane. These different patterns of SUDs reflect the legal status of drugs in different countries. The Scottish survey did not include alcohol misuse as it is a legal drug in Scotland, albeit one associated with considerable harm. In Scotland, a majority of GPs who saw patients with SUDs believed their patients were using recreational (62.1\%) or poly-drug (61.1\%) and 20.5\% considered some patients to be primary psycho-stimulant users. ${ }^{13}$

Referral to clinical guidelines in treating SUD patients was similar between the two studies in PHC $40 \%$ of FPs referred to clinical guidelines and in the Scottish survey $37.1 \%$ referred to guidelines. ${ }^{13}$

Both the Abu Dhabi and Scottish surveys, expressed a positive overall attitude among the responders. Exceptions were in the Abu Dhabi survey where 70\% of PHC FPs thought that drug users should be seen centrally by specialist services and around 50\% reported that they were less confident in the success of treating poly-drug users. Furthermore, the Scottish study identified that more positive attitudes were noted in those GPs currently treating drug misusers, GPs with smaller list sizes and those with specific training for drug misuse.13Two studies explored GPs' attitudes toward alcohol. In the first study, GPs agreed that it was legitimate for them to ask their patients about alcohol consumption and they reported low levels of motivation (43\%), self-esteem (53\%) and satisfaction (15\%) arising from work with problem drinkers. ${ }^{16}$ Another study found mixed attitudes among GPs towards patients who misused alcohol; 65\% believed treating alcohol mis-users was rewarding, $48 \%$ believed it was time consuming and $54 \%$ saw alcohol misuse as presenting major problems. ${ }^{18}$

In EAD, the majority of the FPs did not have any specialised training in treating SUDs. A total $66 \%$ would have liked to have had further training in screening and in the management of substance abuse. The most common training topics FPs expressed interest in were drug dependency screening, treatment, and management in primary care. Similarly, a previous study revealed that only $10.5 \%$ had received some formal SUD training. Most GPs felt that training workshops on management of alcohol misuse, and more support from social services and organisations that specialise in managing alcohol-related problems would benefit them and their patients. ${ }^{18}$ The Scottish study revealed that $38.7 \%$ had specific training in drug dependency and 34\% said that they would have liked further training. ${ }^{13}$ And another study conducted in the UK indicated that around half of the GPs had received less than four hours of post-graduate train- 
ing, continuing medical education or clinical supervision on alcohol and alcohol related problems. ${ }^{16}$

This study helps managers, clinicians and policymakers to understanding barriers to screening for substance disorders in primary healthcare settings. Clear policy direction for screening for SUDs by FPs should be embedded in the healthcare system. Education, training and a supportive work environment need to be provided to ensure and enhance family physicians' familiarity with screening and building their clinical confidence in dealing with patients who seek care. Improving knowledge, however, should not be restricted to primary care physicians, but should extend to medical school curricula as well.

Further research to determine the prevalence of SUDs among primary care patients in the UAE is required. Research on training and on different strategies to engage physicians in the management of patients with substance disorders is also crucial to test their effectiveness and seek possible ways for improvement.

Different tools have been used in different settings and different countries for alcohol and drug screening. The most widely used tool internationally is probably the Alcohol, Smoking and Substance Involvement Screening Test (ASSIST), which is used as part of the Screening Brief Intervention Referral to Treatment (SBIRT) programme which has proved to be effective in several countries including Poland and the USA. ${ }^{19,20}$ The authors are planning to run a controlled trial to test the effectiveness and applicability of this intervention for primary care physicians in the UAE in collaboration with the Abu Dhabi Health Services Company and Ambulatory Healthcare Services.

The study was the first survey of its kind in the UAE and provides baseline data on the nature and extent of the involvement of family physicians in the management of SUDs in the Emirate of Abu Dhabi and indeed the wider Middle East region. The response rate was less than expected. Reasons for this need to be explored but it may be that FPs in the UAE may not be as used to requests to participate in health service studies as FPs in other countries due to a lack of time or interest.

This study has identified the need for increased training for UAE family physicians in detecting and diagnosing SUDs in general practice, further managing their patients' addictions and referring them to specialist care when appropriate. Various strategies should be considered to implement guidelines, and provide training through arrangements with decision makers in primary care.

\section{Acknowledgements}

The authors wish to thank Dr. Mohamed Al Garhy (Consultant Psychiatrist, SKMC), Dr. Fatima Al Darmaki (Director of Niema and Jahili Clinics, Tawam 
Hospital), and Dr. Amal Al-Harbi (Head of Al Khabisi Clinic, Al Ain Hospital) for their assistance to complete this research. We also wish to thank all the GPs who filled in the questionnaires.

\section{Competing interest}

The authors declare that they have no competing interests.

\section{Funding}

Funding: This study was funded by the National Rehabilitation Center.

\section{References}

1. United Nations, New York 2012. World Drug Report 2012 [http://www.unodc.org/unodc/en/data-and-analysis/WDR-2012.html]

2. World Health Organization 2009. Global Health Risks [http://www.who.int/healthinfo/global_burden_disease/GlobalHealthR isks_report_full.pdf]

3. De Micheli D, Fisberg M, Formigoni ML. Study on the effectiveness of brief intervention for alcohol and other drug use directed to adolescents in a primary health care unit. Rev Assoc Med Bras 2004;50(3):305-13. [http://www.ncbi.nlm.nih.gov/pubmed/15499485]

Doi: http://dx.doi.org/10.1590/S0104-42302004000300040

PMid:15499485

4. Pilowsky DJ, Wu L, Screening for alcohol and drug use disorders among adults in primary care: A review. Substance Abuse Rehabilitation 2012;3(1):25-34.

[http://www.ncbi.nlm.nih.gov/pubmed/22553426]

PMid:22553426 PMCid:PMC3339489

5. Coulton S, Drummond C, James D, Godfrey C, Bland J M, Parrott S, Peters T, Stepwice Res Team. Opportunistic screening for alcohol use disorders in primary care: comparative study. British Medical Journal 2006;332(7540):511-17. [http://www.bmj.com/content/332/7540/511.pdf\%2Bhtml]

http://dx.doi.org/10.1136/bmj.38743.421574.7C

PMid:16488896 PMCid:PMC1388125 
6. Polydorou S, Erik W, Gunderson MD, Frances R, Levin MD. Training Physicians to Treat Substance Use Disorders. Curr Psychiatry Rep 2008;10(5):399-404. [http://www.ncbi.nlm.nih.gov/pmc/articles/ PMC2741399/pdf/nihms-129773.pdf]

Doi: http://dx.doi.org/10.1007/s11920-008-0064-8

PMid:18803913 PMCid:PMC2741399

7. Deehan A, Taylor C, Strang J. The general practitioner, the drug misuser, and the alcohol misuser: major differences in general practitioner activity, therapeutic commitment, and 'shared care' proposals. British Journal of General Practice 1997;47:705-09.

[http://europepmc.org/articles/PMC1409931/pdf/brjgenprac000920015.pdf]

\section{PMid:9519515 PMCid:PMC1409931}

8. Glanz, A. Findings of a national survey of the role of general practitioners in the treatment of opiate misuse: views on treatment. British Medical Journal 1986;293:543-545.

[http://www.ncbi.nlm.nih.gov/pmc/articles/PMC1341317/]

Doi: http://dx.doi.org/10.1136/bmj.293.6546.543

PMid:3092911

9. Matheson C, Pitcairn J, Bond CM, Van Teijlingen E, Ryan M. General practice management of illicit drugs users in Scotland: a national survey. Addiction 2003;98(1):119-26

Doi: http://dx.doi.org/10.1046/j.1360-0443.2003.00263.x

PMid:12492763

10. McKeown A, Matheson C, Bond C. A qualitative study of GP's attitudes to drug misusers and drug misuse services in primary care. Family Practice 2003;20(2):120-125

Doi: //dx.doi.org/10.1093/fampra/20.2.120

PMid:12651783 
11. Abu Dhabi Healthcare Services Co. SEHA. Ambulatory healthcare Services [http://www.seha.ae/seha/en/Pages/Ambulatory HealthCare.aspx]

12. AlMarri, T.S.K. et al. Alcohol and Substance use in the Arabian Gulf region: A review. International Journal of Psychology 2009;44(3):22233.

Doi: //dx.doi.org/10.1080/00207590801888752

PMid:22029498

13. Matheson C, Porteous T, Van Teijlingen E, Bond C. Management of drug misuse: an 8-year follow-up survey of Scottish GP's. British Journal of General Practice 2010;60: 517-520. [http://www.ncbi.nlm. nih.gov/pmc/articles/PMC2894381/pdf/bjgp60-517.pdf]

Doi: http://dx.doi.org/10.3399/bjgp10X514783

PMid:20594442 PMCid:PMC2894381

14. Pelet A, Besson J, PØcoud A, Favrat B. Difficulties associated with outpatient management of drug abusers by general practitioners. A crosssectional survey of general practitioners with and without methadone patients in Switzerland. BMC Family Practice 2005;6:51

[http://www.biomedcentral.com/1471-2296/6/51]

Doi:10.1186/1471-2296-6-51.

15. Gates P. Howard J, Sangfai P. Role of general practitioners in provision of brief interventions for cannabis use-related difficulties. 2013;16:110 [http://ncpic.org.au/ncpic/publications/bulletins/article/ncpic-bulletin-16-role-of-general-practitioners-in-provision-of-brief-interventions-for-cannabis-use-related-difficulties]

16. Wilson GB, Lock CA, Heather N, Cassidy P, Christie MM, Kaner EFS. TREATMENT. Intervention against Excessive Alcohol Consumption in Primary Health Care: A Survey of GPs'Attitudes and Practices in England 10 Years On. Alcohol and Alcoholism. 2011;46(5):570-77. [http://www.ncbi.nlm.nih.gov/pmc/articles/PMC3156887/pdf/agr067. pdf]

Doi: http://dx.doi.org/10.1093/alcalc/agr067

PMid:21690169 PMCid:PMC3156887 
17. Matheson C, Aucott L, Pflanz-Sinclair C. General Practitioner Engagement with the Scottish National Naloxone Programme: A Needs Assessment Project January 2013. [http://www.healthscotland.com/documents/6258.aspx]

18. Gurugama NP, Seneviratne SL, Peiris DT, de Silva HJ. Detection and management of alcohol misuse by general practitioners. Ceylon Med J. 2003;48(4):122-24. [http://www.ncbi.nlm.nih.gov/pubmed/15125403]

PMid:15125403

19. Cherpite CJ, Moskalewicz J, Swiatkiewicz G, Ye Y, Bond J. Screening, Brief Intervention, and Referral to Treatment (SBIRT) in a Polish Emergency Department: Three-Month Outcomes of a Randomized, Controlled Clinical Trial. J. Stud. Alcohol Drugs 2009;70:982-90. [http://www.ncbi.nlm.nih.gov/pmc/articles/PMC2776128/pdf/jsad982. pdf]

PMid:19895777

20. Krupski A, Joesch JM, Dunn C, Donovan D, Bumgardner K, Lord SP, Ries $\mathrm{R}$ et al. Testing the effects of brief intervention in primary care for problem drug use in a randomized controlled trial: rationale, design, and methods. Addiction Science \& Clinical Practice 2012;7(1):27.

[http://www.ascpjournal.org/content/pdf/1940-0640-7-27.pdf]

Doi: http://dx.doi.org/10.1186/1940-0640-7-27

PMid:23237456 PMCid:PMC3598998 